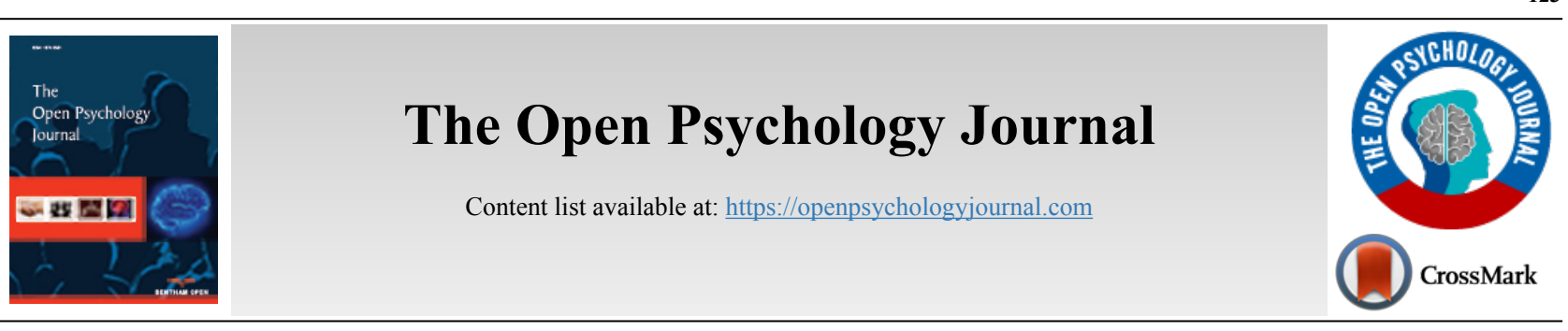

RESEARCH ARTICLE

\title{
Teacher Emotional Support Scale on Italian High School Students: A Con- tribution to the Validation
}

\author{
Luciano Romano ${ }^{1, *}$, Ilaria Buonomo ${ }^{1}$, Antonino Callea ${ }^{1}$, Caterina Fiorilli ${ }^{1}$ and Katerina Schenke ${ }^{2}$ \\ 'Department of Human Sciences, LUMSA University, Rome, Italy \\ ${ }^{2}$ Graduate School of Education \& Information Studies, University of California, Los Angeles, CA, USA
}

\begin{abstract}
:
Background/Objective:

This study represents a contribution to the validity and reliability of the 15-item Teacher Emotional Support Scale in a sample of Italian high school students $(\mathrm{N}=501 ; 80.2 \%$ females; $\mathrm{M}=15.66 ; \mathrm{SD}=1.52)$. Therefore, the present paper aimed to examine the factor structure and to investigate the reliability and validity of the scale. Students' perception of teacher emotional support refers to the students' perception of whether and to what extent the teacher shows caring and understanding behaviours, promotes students' growth and establishes personal relationships with them.

\section{Materials and Methods:}

Confirmatory factor analyses confirmed that the hypothesized three-factor solution had the best fit to the data, assessing three different but related dimensions: Positive climate, Teacher sensitivity, and Regard for adolescent perspective. Furthermore, the reliability and convergent and discriminant validity can be considered adequate.

Conclusion:

The Teacher Emotional Support Scale could be considered as a valid instrument to assess high school students' perception of the emotional support received from their teachers. Practical implications have also been discussed.
\end{abstract}

Keywords: Emotional support, Teachers, High school, Students’ perceptions, Classroom climate, Teacher support.

\begin{tabular}{|l|c|c|c|}
\hline Article History & Received: January 08, 2020 & Revised: April 13, 2020 & Accepted: May 05, 2020 \\
\hline
\end{tabular}

\section{INTRODUCTION}

\subsection{Classroom Climate and Teacher Emotional Support}

In the education sector, there is increasing attention to classroom climate as an indicator of students' well-being and teaching quality [1 - 4]. Although an extensive literature has focused on school climate [5 - 7], considering classroom climate also may serve an important purpose [8]. Whereas school climate refers to the whole facets of school life and environments, from academic to organizational ones, classroom climate strictly refers to the interaction and the atmosphere set both by teachers and students $[4,9,10]$. Thus, classroom climate is understood as the subjective students' perception of every dynamics that take place daily in the classroom [11 - 13] and could be considered as the result of multiple aspects: teacher-students and students-peer relation-

* Address correspondence to this author at the Department of Human Sciences, LUMSA University, P.zza delle Vaschette, 101, 00193, Rome, Italy; Tel: +393471661196; E-mail: 1.romano@lumsa.it ships, educational climate as well as educational practices [9, 14 - 16]. Teachers' emotional support is crucial for students' adjustment and has a pivotal role in classroom climate [17 26]. High school students, indeed, spend most of the time at school, experience new and complex duties, such as exams and tests, utterly different from the ones they have learned to deal with during primary school [27]. Thus, during this period, adolescents are deeply susceptible to the emotional support they received from adults in the school context [28]. The emotional relationship students establish with their teacher, indeed, is strictly related to academic success [29], school and overall life satisfaction [30], and psychological well-being [31]. Teachers' emotional support refers to the ability of a teacher to create positive relationships with their students, promoting their autonomy and competencies as well as their emotional and social functioning [15]. According to one framework from Pianta and Hamre [23], emotional support encompasses three specific dimensions: positive climate, teacher sensitivity, and regard for adolescent perspective. 
Positive climate refers to what extent the teacher creates and promotes positive interactions in the classroom [2, 4, 23]. Teacher sensitivity refers to whether he/she is responsive to the student's emotional, academic, and individual needs [2, 4, 23]. Finally, regard for adolescent perspective refers to how teacher encourages students' autonomy, peer interactions and their social needs [2, 4, 23].

Students in classrooms with emotionally supportive teachers are more engaged, motivated, and show better academic performance than their counterparts [2, 32 - 34]. Conversely, various studies have highlighted the direct link between low levels of teachers' emotional support and adverse academic outcomes, such as anxiety [35-41].

\subsection{Students' Perception of Teacher Emotional Support}

Students' perception of teacher support refers to their perception of whether and to what extent the teacher shows caring and understanding behaviors, promotes students' growth, and establishes personal relationships with them [23, 33, 42]. Students' everyday classroom experience and their perceptions are related to the effectiveness of learning and instructions (see $[15,43$ - 47]). Previous studies have underlined that students who perceive their teachers as high in emotional support also show high general adjustment and several positive outcomes (i.e., high academic achievement, emotional well-being, engagement, prosocial behavior, and peer support) [33, 34, 48 53]. Additionally, there is an inverse relationship between students' perception of teachers' emotional support and negative academic conditions [41, 54 - 57]. For instance, Kim and colleagues [58] have shown that among different sources of support, such as teachers, parents, and peers, teacher's support has the strongest negative relationship to student burnout.

\subsection{The Present Study}

Given the importance of students' perception of teacher emotional support in determining a positive classroom climate $[23,59,60]$, previous studies have shown some limitations. The existing self-report questionnaires, although exploring in some way the high school students' perception of teacher support, give just a little attention to the emotional components and do not provide an in-depth differentiation of the quality of emotional support (e.g., The Child and Adolescent Social Support Scale, CASSS) [61]. Some others, instead, exclusively address special education (e.g., School Climate Inventory, SCI) [62]. Moreover, although the Organisation for Economic Cooperation and Development (OECD) [63] results suggest that Italian students are below the OECD average for students' perception of teacher support, the few Italian instruments that have been published refer to school climate with little or no attention to teacher emotional support (e.g., Questionnaire on Perception of School Climate, SCPQ) [64]. As such, providing a reliable and valid instrument for use on high school students could serve as an important step in understanding student experiences, having a deeper perspective on the quality of teacher emotional support, as well as better designing professional development for teachers [25, $65-68]$. This study represents a contribution to the validity and reliability of the Italian version of the Teacher Emotional Support Scale, used in
Schenke and colleagues [4], and developed by Ryan and Patrick [42]. Although the original scale was designed for students in math classes, we decided to validate the instrument, referring to all the teaching staff. This choice was based on three main theoretical assumptions. First, Italian high school students, as opposed to the American ones where the original scale was tested, do not move from their classrooms for the entire school year, but teachers who taught different subjects move in the classrooms in different hours during the school day. Second, considering the latest Program for International Student Assessment (PISA) results [69], Italian high school students, compared to the other countries involved in the study, present lower scores in all the subjects taken into account (Italian, Sciences, and Mathematics). Furthermore, $57 \%$ of Italian High school students ( $21 \%$ in the OECD average) have skipped a day of school in the two weeks before the PISA test, and this index is usually related to lack of support and poor classroom climate [69]. Third, previous studies have shown the efficacy of interventions based on the three facets, regardless of the subject taught [70]. Thus, especially in the Italian context, there is a need to provide a scale that measures students' perception of teachers' emotional support, and that is not subordinated to a single subject taught. Therefore, the present paper aimed to examine the factor structure and to investigate the reliability and validity of the scale. Firstly, the factor structure of the Italian version of the Teacher Emotional Support Scale was tested by comparing the goodness-of-fit of some alternative models. Specifically, the hypothesized model composed of three correlated factors (i.e., positive climate, teacher sensitivity, and regard for adolescent perspective) would better describe teachers' emotional support in the classroom than a one-factor model (general emotional support) or a two-factor model. Secondly, the reliability of each dimension was investigated through Cronbach's alpha coefficient. Thirdly, the convergent and discriminant validity of Teacher Emotional Support Scale was investigated by examining its associations with school engagement dimensions (such as vigor, dedication, and absorption), classmate support (i.e., given social support and perceived social support), academic anxiety, and school burnout symptoms (i.e., emotional exhaustion, cynicism, and sense of inadequacy).

\section{MATERIALS AND METHODS}

\subsection{Participants}

This study used a cross-sectional descriptive design with convenience sampling. Participants were 501 Italian high school students $(80.2 \%$ females; $\mathrm{M}=15.66 ; \mathrm{SD}=1.52)$. In detail, students came from 26 classes and attended two different high schools from Central and Southern Italy: $60.6 \%$ belong to human sciences high school (90\% females) and 30.4\% high school specializing in classics subjects (57.9\% females). Concerning school enrollment and considering that Italian high school lasts five years, $17.8 \%$ of the students attend the first year, $32.5 \%$ the second year, $19.8 \%$ the third year, $12.5 \%$ the fourth year, and $17.4 \%$ the last year. The research protocol was approved by the school council, and a letter describing the aim of the study and the informed consent form was provided to the parents of the students. Only participants whose parents 
provided informed consent took part in the study. All the participants freely consented to answer the questionnaires.

\subsection{Procedure}

Considering that Italian students follow lessons in the same classroom during the whole school year, participants completed the questionnaires in their own classrooms, during school hours and in a single session, with a paper-pencil approach. A member of the research team was present in case of need and gave all the necessary information to complete the questionnaire before starting. To avoid as much as possible social desirability bias, we informed all students that the questionnaires were anonymous, collected data were only used for research purposes, and that any teachers were able to view the responses. Teachers were not present in classrooms during the collected data to guarantee spontaneous responses.

Moreover, there was no specific or at-risk condition the researcher was aware of before the administrations. Thus, the first contact between the researcher and the students occurred on the day of data collection.

The research method complied with the norms of the Code of Ethics of the Italian Psychology Association [71], and anonymity and confidentiality standards were assured for all participants.

\subsection{Instruments}

\subsubsection{Teacher Emotional Support}

Teacher emotional support was evaluated by the Emotional Support Scale used in Schenke and colleagues [4]. The translation of the questionnaire followed the step below: Two native Italian-speaking educational researchers translated the items. Their translation was reviewed by Italian-speaking experts in educational research. Back translation of the questionnaire was then performed by a professional bilingual translator who was not involved in the initial translation. Finally, a comparison of the back-translated version and the original version of the questionnaire was performed by both Italian- and English-speaking natives.

The questionnaire consists of 15 items on a 5-point Likert scale (1= "Not at all true", 5= "Very true"), measuring students' perception of the teacher's emotional support. It evaluates three dimensions: Positive Climate, Teacher Sensitivity, and Regard for Adolescent Perspective. Positive Climate refers to students' perception of whether their teacher is creating a positive emotional connection with them. It consists of 5 items (e.g., "Our teacher wants students in this class to respect each other's ideas"). Teacher Sensitivity refers to what extent teachers pay attention to students' individual and academic needs; it consists of 6 items (e.g., "Our teacher cares about how we feel"). Finally, Regard for Adolescents Perspectives refers to how teachers consider the social needs of students and promote interactions with peers. It encompasses 4 items (e.g., "Our teacher encourages us to share ideas with one another in class"). In the original study [4], Cronbach's alpha was 0.82 for Positive Climate, 0.85 for Teacher Sensitivity, and 0.80 for Regard for Adolescent Perspective.

\subsubsection{Classmate Support}

Classmate support was evaluated by the Italian Questionnaire for Given and Perceived Social Support within Peer Relationships at School [72]. This questionnaire consists of 9 items on a 5-points Likert scale (1= "Never", 5= "Always") evaluating two dimensions: Given Social Support and Perceived Social Support. Example of Given Social Support is: "How often do you try to help your classmates when they are in need?"; an example of Perceived Social Support is: "How often your classmates try to cheer you up when you are sad?". In the current study, the Cronbach's alphas were 0.80 for Given social support and 0.87 for Perceived social support.

\subsubsection{School Engagement}

School engagement was evaluated by the Italian validated version of the Utrecht Work Engagement Scale for Students (UWES-S17) [73]. UWES-S is based on 17 items on a 7points Likert scale ( $0=$ "Never", $6=$ "Always"), evaluating three dimensions: Vigor, Dedication, and Absorption. Examples of Vigor subscale is: "In my schoolwork, I feel that I am bursting with energy; an example of Dedication subscale is: "I find my schoolwork full of meaning and purpose"; an example of Absorption subscale is: "When I am studying, I forget everything else around me". In the current study, the Cronbach's alpha was 0.83 for Vigor, 0.93 for Dedication and 0.81 for Absorption.

\subsubsection{School Burnout}

School burnout was assessed via the Italian validated version of the School Burnout Inventory (SBI) [74]. SBI consists of 9 items on a 6-points Likert scale $(1=$ "I totally disagree", 6 = "I totally agree"). It evaluates three dimensions (i.e., Emotional Exhaustion, Cynicism, and Sense of Inadequacy). Example of Emotional Exhaustion subscale is "I often sleep poorly because of all the problems related to the study "; an example of Cynicism subscale is: "I feel like I'm losing interest in school"; an example of Sense of Inadequacy subscale is "I used to have higher expectations of my schoolwork than I do now". In the current study, the Cronbach's alpha was 0.77 for Emotional exhaustion, 0.79 for Cynicism and 0.60 for Sense of inadequacy.

\subsubsection{Academic Anxiety}

Academic anxiety was measured by the anxiety subscale of the Italian Questionnaire for Anxiety and Resilience (QAR) [75]. The Anxiety subscale consists of 7 items evaluating through a 5-point Likert scale ( 1 = "Never", 5 = "Always"). An example of the anxiety subscale is: "Just thinking about exams or tests makes me anxious". In the current study, Cronbach's alpha was 0.86 .

\subsection{Data Analyses}

First, we performed an item analysis to investigate the items' psychometric properties. Item analysis allows observing the characteristics (mean, standard deviation, skewness and kurtosis) of each item and deleting nondiscriminant items, i.e., those items that show extreme means and nearly zero standard deviation and that had skewness and kurtosis higher than $|2|$ [76]. 
Second, we performed Confirmatory Factor Analysis (CFA) using Mplus 6.54 [77] on the three-factor model (M1) to assess whether the factor structure of the Italian version of the Teacher Emotional Support Scale replicated the original theorized structure [4]. We compared M1 with alternative models, i.e., a mono-factorial structure (M2) or a two-factor structure, obtained by combining two of the three dimensions (M3, M4 and M5). All models were tested using the maximum likelihood estimation method. We used the following goodness-of-fit indexes to assess the model: the Root Mean Square Error of Approximation $(R M S E A<.08)$, the Standardized Root Mean Square Residual $(S R M R<.08)$, the Comparative Fit Index $(C F I \geq .95)$ and Tucker Lewis Index (TLI) [78]. However, CFI and TLI values between .90 and .95 should be considered acceptable [79]. We performed the models' comparison by computing a $\chi^{2}$ difference test [80], which indicates whether a given model (M1) fits significantly better or worse than alternative models. Specifically, a significant $\chi^{2}$ difference suggests that the fit indexes of the alternative model are significantly worse than M1. Third, we tested the internal consistency reliability of the scale through Cronbach's alpha coefficient. For Cronbach's alpha interpretation, George and Mallery [81] provided the following rules: $\alpha>0.9=$ Excellent, $\alpha>0.8=$ Good, $\alpha>0.7=$ Acceptable, $\alpha>0.6=$ Questionable, $\alpha>0.5=$ Poor, and $\alpha<0.5$ $=$ Unacceptable. Finally, to assess convergent and discriminant validity, we calculated correlations between dimensions of Teacher Emotional Support Scale and other measures, and Average Variance Extracted (AVE). AVE indicates the level of variance captured by a latent variable versus the level due to the measurement error of its indicator. Specifically, following the procedure developed by Fornell and Larcker [82], AVE is the mean of the sum of lambda squares. The AVE values are included between 0 and 1 . The square root of the AVE is considered acceptable when higher than 0.50 , i.e., more than $50 \%$ of the variance of the latent variable is due to its indicators [82]. Convergent and discriminant validity were supported if the square root of the AVE for each latent variable is higher than its correlation with other constructs.

\section{RESULTS}

\subsection{Descriptive Statistics and Correlations}

Table 1 shows the results of item analysis (descriptive statistics).

The results showed the means ranging from 2.48 and 4.10 . The items with low means were i9 ("Our teachers take a personal interest in students"; Teacher Sensitivity dimension), i2 ("Our teachers treat everyone in this math class fairly", Positive Climate dimension), i6 ("Our teachers care about how we feel", Teacher Sensitivity dimension), i8 ("Our teachers consider students' feelings", Teacher Sensitivity dimension), i12 ("Our teachers encourage us to help other students with their works", Regard for Adolescent Perspective dimension), while highest mean items were il ("Our teachers want students in this class to respect each other's ideas, Positive Climate dimension), i5 ("Our teachers want all students to feel respected", Positive Climate dimension), i3 ("Our teachers want the students in this class to work well together", Positive Climate dimension). Therefore, no item had extreme means or a standard deviation close to zero.

Furthermore, skewness and kurtosis were below $|2|$. Therefore, no items were deleted.

\subsection{Confirmatory Factor Analysis}

Table 2 reports the goodness-of-fit indexes and $\chi^{2}$ difference.

Table 1. Item descriptive statistics, item analyses and factor loadings from the exploratory factor analysis of the Italian version of Teacher Emotional Support Scale.

\begin{tabular}{|c|c|c|c|c|}
\hline Item & M & SD & SK & KU \\
\hline Positive Climate & - & - & - & - \\
\hline $\begin{array}{l}\text { 1. Our teachers want students in this class to respect each other's ideas (I nostri insegnanti vogliono che in questa classe } \\
\text { ciascun studente rispetti le idee dell'altro) }\end{array}$ & 4.10 & 1.10 & -1.17 & 0.57 \\
\hline 2. Our teachers treat everyone in this math class fairly (I nostri insegnanti in questa classe trattano tutti in modo equo) & 2.58 & 1.35 & 0.34 & -1.12 \\
\hline $\begin{array}{l}\text { 3. Our teachers want the students in this class to work well together (I nostri insegnanti vogliono che gli studenti in questa } \\
\text { classe lavorino bene insieme) }\end{array}$ & 4.07 & 1.06 & -1.04 & 0.36 \\
\hline $\begin{array}{l}\text { 4. Our teachers do not allow students to make fun of other students' ideas in class (I nostri insegnanti non permettono che in } \\
\text { questa classe gli studenti si prendano gioco delle idee degli altri studenti) }\end{array}$ & 3.74 & 1.25 & -0.69 & -0.65 \\
\hline 5. Our teachers want all students to feel respected (I nostri insegnanti vogliono che tutti gli studenti si sentano rispettati) & 4.09 & 1.05 & -1.05 & 0.45 \\
\hline Teacher Sensitivity & - & - & - & - \\
\hline 6. Our teachers care about how we feel (Ai nostri insegnanti interessa sapere come ci sentiamo) & 2.60 & 1.18 & 0.37 & -0.69 \\
\hline $\begin{array}{l}\text { 7. We can count on our teachers for help when we need it (Possiamo contare sull'aiuto dei nostri insegnanti in caso di } \\
\text { bisogno) }\end{array}$ & 2.99 & 1.24 & 0.14 & -0.89 \\
\hline 8. Our teachers consider students' feelings (I nostri insegnanti prendono in considerazione i sentimenti degli studenti) & 2.61 & 1.12 & 0.36 & -0.64 \\
\hline 9. Our teachers take a personal interest in students (I nostri insegnanti si interessano personalmente agli studenti) & 2.48 & 1.12 & 0.46 & -0.59 \\
\hline $\begin{array}{l}\text { 10. Our teachers are available to help students when we have questions (I nostri insegnanti sono disponibili ad aiutare gli } \\
\text { studenti se abbiamo delle domande) }\end{array}$ & 3.68 & 1.14 & -0.50 & -0.69 \\
\hline $\begin{array}{l}\text { 11. Our teachers take the time to completely answer our questions (I nostri insegnanti dedicano tutto il tempo necessario per } \\
\text { rispondere completamente alle nostre domande) }\end{array}$ & 2.97 & 1.16 & 0.08 & -0.86 \\
\hline Regard for Adolescent Perspective & - & - & - & - \\
\hline
\end{tabular}


(Table 1) cont.....

\begin{tabular}{|c|c|c|c|c|}
\hline Item & M & SD & SK & KU \\
\hline $\begin{array}{l}\text { 12. Our teachers encourage us to help other students with their works (I nostri insegnanti ci incoraggiano ad aiutare gli altri } \\
\text { studenti con i loro compiti) }\end{array}$ & 2.63 & 1.16 & 0.29 & -0.80 \\
\hline $\begin{array}{l}\text { 13. Our teachers allow us to discuss our work with classmates (I nostri insegnanti ci permettono di discutere il nostro lavoro } \\
\text { con i compagni di classe) }\end{array}$ & 2.81 & 1.14 & 0.22 & -0.70 \\
\hline 14. My teachers listen to what I have to say (I miei insegnanti ascoltano ciò che ho da dire) & 3.13 & 1.20 & -0.10 & -0.87 \\
\hline $\begin{array}{c}\text { 15. Our teachers encourage us to share ideas with one another in class (I nostri insegnanti ci incoraggiano a condividere le } \\
\text { nostre idee con gli altri compagni di classe) }\end{array}$ & 3.25 & 1.20 & -0.22 & -0.82 \\
\hline
\end{tabular}

Note: $\mathrm{M}=$ Mean; $\mathrm{SD}=$ Standard Deviation; $\mathrm{SK}=$ Skewness; KU = Kurtosis.

In brackets the item of the Teacher Emotional Support Scale.

In line with theoretical assumptions, the three-factor model (M1) reached the criteria for fit adequacy: CFI $=0.918$, TLI $=$ $0.901, R M S E A=0.086$, and $S R M R=0.063$. Furthermore, the comparison among models showed that hypothesized threefactor model (M1) was significantly better than other alternative models (M2-M1: $\Delta \chi^{2}=351.78, \Delta \mathrm{df}=3, p=<.001$; M3-M1: $\Delta \chi^{2}=233.79, \Delta \mathrm{df}=1, p=<.001 ; \mathrm{M} 4-\mathrm{M} 1: \Delta \chi^{2}=$ $310.17, \Delta \mathrm{df}=1, p=<.001$; M5-M1: $\Delta \chi^{2}=327.45, \Delta \mathrm{df}=1, p=$ $<.001)$.
As Fig. (1) shows, the standardized solution of the threefactor model showed that standardized estimates of factor loadings were high, ranging from 0.51 and 0.87 , with significant $t$ values and small standard errors. Furthermore, Positive Climate was positively and significantly related to Teacher Sensitivity $(r=.66, p<.01)$ and to Regard for Adolescent Perspective $(r=.67, p<.01)$, as well as Teacher Sensitivity was positively and significantly related to Regard for Adolescent Perspective $(r=.81, p<.01)$.
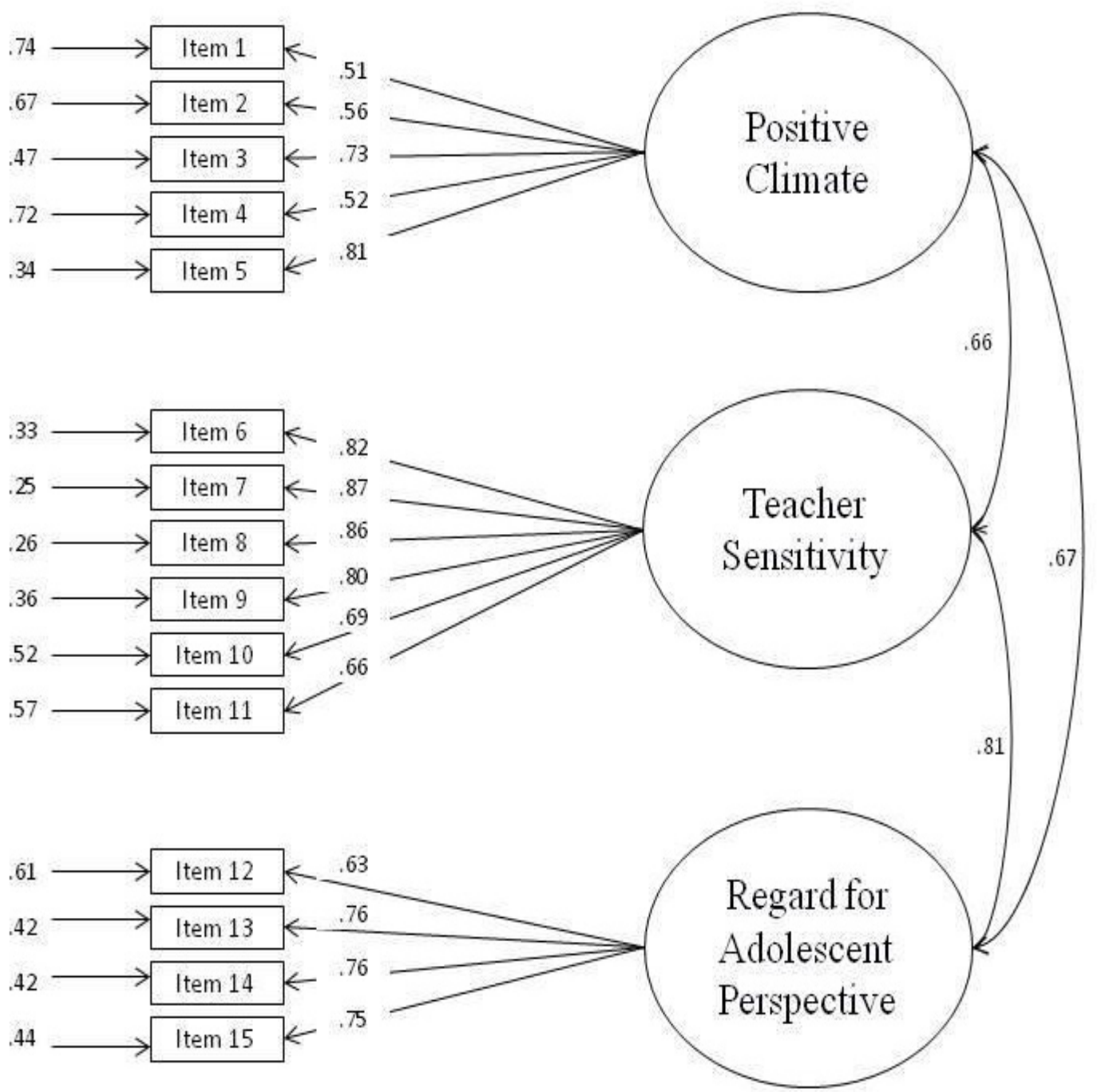

Fig. (1). Results of confirmatory factor analysis of three-factor model. 
Table 2. Summary of goodness-of-fit indexes for confirmatory factor analysis models.

\begin{tabular}{|c|c|c|c|c|c|c|c|c|c|c|}
\hline- & $\chi^{2}$ & df & CFI & TLI & RMSEA & SRMR & Model Comparison & $\Delta \chi^{2}$ & $\Delta \mathbf{d f}$ & $p$ \\
\hline M1: Hypothesized 3-factor model & 406.82 & 87 & .918 & .901 & .086 & .063 & - & - & - & - \\
\hline M2: 1-factor model & 758.60 & 90 & .829 & .801 & .122 & .072 & M2-M1 & 351.78 & 3 & $<.001$ \\
\hline M3: 2-factor model PC+TS, RAP & 640.61 & 89 & .859 & .834 & .111 & .070 & M3-M1 & 233.79 & 1 & $<.001$ \\
\hline $\begin{array}{c}\text { M4: 2-factor model } \\
\text { PC+RAP, TS }\end{array}$ & 716.99 & 89 & .840 & .811 & .119 & .069 & M4-M1 & 310.17 & 1 & $<.001$ \\
\hline $\begin{array}{c}\text { M5: 2-factor model } \\
\text { TS+RAP, PC }\end{array}$ & 734.27 & 89 & .835 & .806 & .120 & .068 & M5-M1 & 327.45 & 1 & $<.001$ \\
\hline
\end{tabular}

Note. $\mathrm{PC}=$ Positive Climate; $\mathrm{TS}=$ Teacher Sensitivity; RAP $=$ Regard for Adolescent Perspective.

Table 3. Correlations among the studied variables.

\begin{tabular}{|c|c|c|c|}
\hline- & PC & TS & RAP \\
\hline Vigor & $.18^{* *}$ & $.31^{* *}$ & $.32^{* *}$ \\
\hline Dedication & $.32^{* *}$ & $.38^{* *}$ & $.38^{* *}$ \\
\hline Absorption & $.18^{* *}$ & $.29^{* *}$ & $.27^{* *}$ \\
\hline Given social support & $.24^{* *}$ & $.19^{* *}$ & $.23^{* *}$ \\
\hline Perceived social support & $.31^{* *}$ & $.25^{* *}$ & $.31^{* *}$ \\
\hline Academic anxiety & -.04 & $-.17^{* *}$ & -.06 \\
\hline Emotional exhaustion & $-.28^{* *}$ & $-.34^{* *}$ & $-.25^{* *}$ \\
\hline Cynicism & $-.25^{* *}$ & $-.33^{* *}$ & $-.27^{* *}$ \\
\hline Sense of inadequacy & $-.22^{* *}$ & $-.35^{* *}$ & $-.27^{* *}$ \\
\hline Square root of the AVE & .64 & .79 & .73 \\
\hline
\end{tabular}

Note. PC $=$ Positive Climate; TS $=$ Teacher Sensitivity; RAP = Regard for Adolescent Perspective

$* * p<.01$ level (2-tails)

$* p<.05$ level (2-tails).

\subsection{Reliability and Convergent and Discriminant Validity}

Reliability, assessing through Cronbach's alphas, showed good internal consistency for each scale, i.e. Positive Climate (five items, $\alpha=.74$ ), Teacher Sensitivity (six items, $\alpha=.90$ ) and Regard for Adolescent Perspective (four items, $\alpha=.81$ ).

Table 3 shows the results of convergent and discriminant validity.

With regards to convergent validity, results revealed significant positive correlations among Positive Climate, Teacher Sensitivity, and Regard for Adolescent Perspective and the three dimensions of School engagement (Vigor, Dedication, and Absorption). Furthermore, Positive Climate, Teacher Sensitivity, and Regard for Adolescent Perspective were positively and significatively related to Given Social Support and Perceived Social Support.

With regard to discriminant validity, the three dimensions of the Teacher Emotional Support Scale were moderately and negatively correlated to the three dimensions of SBI (Emotional Exhaustion, Cynicism, and Sense of Inadequacy). Moreover, while Academic Anxiety was moderately and negatively correlated with Teacher Sensitivity, there were no significant correlations to the other two dimensions of the Teacher Emotional Support Scale $(p>0.05)$. Therefore, these results support the convergent and discriminant validity of the Teacher Emotional Support Scale. Finally, we calculated and reported in Table 3, the square root of the AVE for each dimension. The three square roots of the AVE was higher than .50 , supporting good convergent validity. However, they were slightly lower than correlations to other constructs (Fig. 1).
Therefore, the discriminant validity of the three dimensions was not fully supported. Indeed, although Positive Climate was sufficiently distinct from the other two factors, the measurements of Teacher Sensitivity and Regard for Adolescent Perspective may partially overlap. Therefore, we also requested modifications indices, in order to investigate as a three-factor model may improve. Results of modifications indices showed that only the item 14 ("My teachers listen to what I have to say"), measuring Regard for Adolescent Perspective, significantly improves fit indices if it was also loaded to Teacher Sensitivity. Therefore, the overlapping may be limited to this item.

\section{DISCUSSION}

The purpose of this study was both to validate the Teacher Emotional Support Scale from Schenke and colleagues [4] and developed by Ryan and Patrick [42] to the Italian academic context, and to evaluate its psychometric properties, investigating its dimensionality, reliability and convergent and discriminant validity. Our findings have suggested that Teacher Emotional Support Scale is a valid and reliable scale to measure students' perception of teachers' emotional support in the classroom. Our study represents the first Italian validation of a self-report questionnaire concerning students' perception of teacher emotional support. Furthermore, and to the best of our knowledge, this instrument is the first to provide a clear and specific distinction of the different facets of teacher emotional support a student could perceive in his/her daily school life. Details about the results were discussed in the sections below. 


\subsection{Factorial Structure of the Model}

We investigated the latent structure of the scale by comparing a series of alternative factorial models: the hypothesized three-factor model, a one-factor model (general emotional support), and a two-factor model (obtained by combining two of the three dimensions). The high correlation between two of the three dimensions of the scale (teacher sensitivity and regard for adolescent perspective) lead us to test the two-factor model. Despite the high correlation, results from the factor analysis suggest the separation of these two dimensions, showing that the three-factor-solution had the best fit for the data. Following the original study [4], positive climate, teacher sensitivity, and regard for the adolescent perspective better represent teacher emotional support and are closely related, but separate constructs. Previous studies, indeed, have shown that students who perceived a high positive climate also report lower dropouts rates and higher academic achievement $[29,83]$, and that perceived teacher sensitivity was related to higher vocabulary and decoding skills [84]. Moreover, other evidence suggests that students who perceived their teachers promoting autonomy in the classroom also reported higher levels of engagement [85]. These findings further support the three-dimensionality of perceived teacher emotional support and suggest that specific difficulties in the academic context could depend on gaps in specific areas of teacher emotional support. Besides, taking into account the distinction of the three dimensions could help to target specific training courses for teachers, focused on the single facets of the emotional support that should have to be improved in their respective classrooms.

\subsection{Convergent and Discriminant Validity}

In order to investigate the convergent and discriminant validity of the Teacher Emotional Support Scale, we examine its associations with School Engagement dimensions, Classmate Support, Academic Anxiety, and School Burnout symptoms. Our findings showed that both Engagement dimensions and Given and Perceived Social Support from Classmates were positively associated with Teacher Emotional Support dimensions: the higher teachers gave emotional support to their students, the higher students felt engaged, gave support to classmates, and received it back. In detail, and in line with previous findings [48, 53, 86, 87], students are more dedicated to the school context when teachers take care of their feelings and promote their social interaction and development. Furthermore, correlation results revealed differences in the magnitude of the coefficients across the dimensions of the Teacher Emotional Support Scale. For instance, considering UWES dimensions, Vigor and Absorption showed a weaker relationship with Positive Climate, when compared to the other dimensions of the scale. The same state could be observed considering the relationship among Given social support and each dimension of the scale. These findings suggest that Positive Climate, Teacher Sensitivity, and Regard for Adolescent Perspective are related but different constructs.

Moreover, while school burnout dimensions were negatively related to all the teacher's emotional support dimensions, academic anxiety was only (negatively) related to teacher sensitivity. This unexpected result could be better understood in light of the definition of the discriminant validity of Pedon [88], which asserts that discriminant validity is stronger when no relationships between the two measures considered are in place. Furthermore, the evidence that each dimension of the construct is related to the same outcome in different ways, as for academic anxiety, strongly supports the three-dimensionality of the Teacher Emotional Support Scale.

Furthermore, convergent validity was further supported by the results of the square root of the AVE, which suggested that more than $50 \%$ of the variance of the latent variable is due to its indicators rather than measurement error. However, the discriminant validity of three factors was not fully supported, specifically due to the high correlation between Teacher Sensitivity and Regard for Adolescent Perspective. The results of comparison among different factor models, however, clearly showed that the hypothesized three-factor model better fitted than other alternative models. Specifically, also the fit indices of the two-factor model (M5) - with a factor only composed of items of Positive Climate and the other factor composed of all items of Teacher Sensitivity and Regard for Adolescent Perspective - were significantly worse.

\subsection{Limitations and Suggestions for Future Research}

There are some limitations to this study that are important to note. First, due to the imbalanced sample, the generalization of results based on gender should be managed with caution. For future research, it would be interesting to replicate the present study with a gender-balanced sample. Moreover, participants are from Central and Southern Italy, and they are not representative of the whole Country. Finally, it could be interesting for further researches to include other Italian high schools' educational programs in order to have a deeper frame of the studied variables in the Italian academic context. Finally, although our results suggested that the Italian version of the Teacher Emotional Support Scale is a reliable and valid instrument to measure three hypothesized dimensions, further studies are necessary to support discriminant validity.

\section{CONCLUSION}

In conclusion, the Teacher Emotional Support Scale could be useful to understand if students perceived their teachers as emotionally supportive, especially to what extent they are able to create a positive climate in the classroom, as well as respond to students' emotional and social needs. This instrument, in addition to observational measures [2], could offer a more extensive understanding of classroom climate and teacherstudent relationships, giving more attention to students' points of view. The scale aims to be a valid instrument for teachers to figure out what they have to enhance with students to strengthen their relationship. Furthermore, in light of the showed link between teacher emotional support and significative facets of students' daily life, further studies should be conducted to deepen these aspects. The insight into the dynamics of this relation (considering, for instance, the role of classmates support and engagement) could facilitate educators, practitioners, and psychologists to plan specific preventive measures in classrooms to ensure the onset of adverse school outcomes. 


\section{ETHICS APPROVAL AND CONSENT TO PARTI- CIPATE}

The research protocol was approved by the Ethics Committee of the Lumsa University of Rome, Italy.

\section{HUMAN AND ANIMAL RIGHTS}

No Animals were used in this research. All human research procedures followed were in accordance with the ethical standards of the committee responsible for human experimentation (institutional and national), and with the Helsinki Declaration of 1975, as revised in 2013.

\section{CONSENT FOR PUBLICATION}

Informed consent was taken from the parents before the participants were enrolled in the study.

\section{AVAILABILITY OF DATA AND MATERIALS}

The datasets generated for this study are available on request to the corresponding author [L.R] upon reasonable request.

\section{FUNDING}

None.

\section{CONFLICT OF INTEREST}

The authors declare no conflict of interest, financial or otherwise

\section{AKNOWLEDGEMENTS}

Declared none.

\section{REFERENCES}

[1] Avant TS, Gazelle H, Faldowski R. Classroom emotional climate as a moderator of anxious solitary children's longitudinal risk for peer exclusion: A child $\times$ environment model. Dev Psychol 2011; 47(6): 1711-27.

[http://dx.doi.org/10.1037/a0024021] [PMID: 21688897]

[2] Pianta RC, Hamre BK, Mintz SL. The CLASS-secondary manual. Charlottesville, VA: University of Virginia 2012

[3] Pianta RC, La Paro KM, Hamre BK. Classroom Assessment Scoring System (CLASS): K-3. Baltimore, MD: Brookes 2008.

[4] Schenke K, Lam AC, Conley AMM, Karabenick SA. Adolescents' help seeking in mathematics classrooms: Relations between achievement and perceived classroom environmental influences over one school year. Contemp Educ Psychol 2015; 41: 133-46.

[http://dx.doi.org/10.1016/j.cedpsych.2015.01.003]

[5] Berkowitz R, Moore H, Astor RA, Benbenishty R. A Research synthesis of the associations between socioeconomic background, inequality, school climate, and academic achievement. Rev Educ Res 2017; 87(2): 425-69 [http://dx.doi.org/10.3102/0034654316669821]

[6] Gage NA, Larson A, Sugai G, Chafouleas SM. Student perceptions of school climate as predictors of office discipline referrals. Am Educ Res J 2016; 53(3): 492-515.

[http://dx.doi.org/10.3102/0002831216637349]

[7] Rudasill KM, Snyder KE, Levinson H. L. Adelson J. Systems view of school climate: a theoretical framework for research. Vol. 30, Edu Psychol Rev. Springer New York 2018; LLC: 35-60.

[8] Wang M T, Degol JL. School climate: A review of the construct, measurement, and impact on student outcomes. Vol. 28, Edu Psychol Rev. Springer New York 2016; LLC: 315-52.

[9] Kaplan Toren N, Seginer R. Classroom climate, parental educational involvement, and student school functioning in early adolescence: a longitudinal study. Soc Psychol Educ 2015; 18(4): 811-27. [http://dx.doi.org/10.1007/s11218-015-9316-8]

[10] Villares E, Mariani M, Sink CA, Colvin K. Multilevel confirmatory factor analysis of the teacher my class inventory-short form. Meas Eval Couns Dev 2016; 49(4): 263-73.

[http://dx.doi.org/10.1177/0748175616639107]

[11] Kaufmann R, Sellnow DD, Frisby BN. The development and validation of the Online Learning Climate Scale (OLCS). Commun Educ 2016; 65(3): 307-21.

[http://dx.doi.org/10.1080/03634523.2015.1101778]

[12] López-González L, Amutio A, Oriol X, Bisquerra R. Hábitos relacionados con la relajación y la atención plena (mindfulness) en estudiantes de secundaria: Influencia en el clim. Rev Psicodidact 2016; 21(1): 121-38.

[http://dx.doi.org/10.1387/RevPsicodidact.13866]

[13] Virtanen TE, Pakarinen E, Lerkkanen M-K, Poikkeus A-M, Siekkinen M, Nurmi J-E. A validation study of classroom assessment scoring system-secondary in the finnish school context. J Early Adolesc 2018; 38(6): 849-80.

[http://dx.doi.org/10.1177/0272431617699944]

[14] Rimm-Kaufman SE, La Paro KM, Downer JT, Pianta RC. The contribution of classroom setting and quality of instruction to children's behavior in kindergarten classrooms. Elem Sch J 2005; 105(4): 377-94

[http://dx.doi.org/10.1086/429948]

[15] Schenke K, Ruzek E, Lam AC, Karabenick SA, Eccles JS. Heterogeneity of student perceptions of the classroom climate: A latent profile approach. Learn Environ Res 2017; 20(3): 289-306 [http://dx.doi.org/10.1007/s10984-017-9235-z]

[16] Buonomo I, Fiorilli C, Benevene P. The impact of emotions and hedonic balance on teachers' self-efficacy: Testing the bouncing back effect of positive emotions. Front Psychol 2019; 10: 1670.

[http://dx.doi.org/10.3389/fpsyg.2019.01670] [PMID: 31379687]

[17] Birch SH, Ladd GW. Children's interpersonal behaviors and the teacher-child relationship. Dev Psychol 1998; 34(5): 934-46. [http://dx.doi.org/10.1037/0012-1649.34.5.934] [PMID: 9779740]

[18] Cheema J, Kitsantas A. Predicting high school student use of learning strategies: The role of preferred learning styles and classroom climate. Educ Psychol 2016; 36(5): 845-62.

[http://dx.doi.org/10.1080/01443410.2014.981511]

[19] Fast LA, Lewis JL, Bryant MJ, et al. Does math self-efficacy mediate the effect of the perceived classroom environment on standardized math test performance? J Educ Psychol 2010; 102(3): 729-40. [http://dx.doi.org/10.1037/a0018863]

[20] Fiorilli C, Pepe A, Buonomo I, Albanese O. At-risk teachers: The association between burnout levels and emotional appraisal processes. Open Psychol J 2017; 10(1): 127-39.

[http://dx.doi.org/10.2174/1874350101710010127]

[21] Hamre BK, Pianta RC. Early teacher-child relationships and the trajectory of children's school outcomes through eighth grade. Child Dev 2001; 72(2): 625-38.

[http://dx.doi.org/10.1111/1467-8624.00301] [PMID: 11333089]

[22] Hamre BK, Pianta RC. Classroom environments and developmental processes: Conceptualization and measurement. Handbook of research on schools, schooling and human development. Taylor and Francis 2010; pp. 25-41.

[23] Pianta RC, Hamre BK. Conceptualization, measurement, and improvement of classroom processes: Standardized observation can leverage capacity. Educ Res 2009; 38(2): 109-19. [http://dx.doi.org/10.3102/0013189X09332374]

[24] Quaglia R, Gastaldi FGM, Prino LE, Pasta T, Longobardi C. The pupil-teacher relationship and gender differences in primary school. Open Psychol J 2014; 6(1): 69-75.

[http://dx.doi.org/10.2174/1874350101306010069]

[25] Ruzek EA, Hafen CA, Allen JP, Gregory A, Mikami AY, Pianta RC How teacher emotional support motivates students: The mediating roles of perceived peer relatedness, autonomy support, and competence. Learn Instr 2016; 42: 95-103.

[http://dx.doi.org/10.1016/j.learninstruc.2016.01.004] [PMID: 28190936]

[26] Yeung R, Leadbeater B. Adults make a difference: The protective effects of parent and teacher emotional support on emotional and behavioral problems of peer-victimized adolescents. J Community Psychol 2010; 38(1): 80-98. [http://dx.doi.org/10.1002/jcop.20353]

[27] Meylan N, Meylan J, Rodriguez M, Bonvin P, Tardif E. What types of educational practices impact school burnout levels in adolescents? Int J Environ Res Public Health 2020; 17(4): 1152. 
[http://dx.doi.org/10.3390/ijerph17041152] [PMID: 32059560]

[28] Wentzel KR, Russell S, Baker S. Emotional support and expectations from parents, teachers, and peers predict adolescent competence at school. J Educ Psychol 2016; 108(2): 242-55.

[http://dx.doi.org/10.1037/edu0000049]

[29] Allen J, Gregory A, Mikami A, Lun J, Hamre B, Pianta R. Observations of effective teacher-student interactions in secondary school classrooms: Predicting student achievement with the classroom assessment scoring system-secondary. School Psych Rev 2013; 42(1): 76-98.

\section{[PMID: 28931966}

[30] Zullig KJ, Ward RM, Scott Huebner E, Daily SM. Association between adolescent school climate and perceived quality of life. Child Indic Res 2018; 11(6): 1737-53.

[http://dx.doi.org/10.1007/s12187-017-9521-4]

[31] Pössel P, Rudasill KM, Sawyer MG, Spence SH, Bjerg AC. Associations between teacher emotional support and depressive symptoms in Australian adolescents: A 5-year longitudinal study. Dev Psychol 2013; 49(11): 2135-46.

[http://dx.doi.org/10.1037/a0031767] [PMID: 23379297]

[32] Brackett M A, Patti J, Stern R, et al. A sustainable skill-based approach to developing emotionally literate schools. In: The Handbook for Developing Emotional and Social Intelligence: Best Practices, Case Studies, and Strategies. 2008; pp. 329-58.

[33] Reyes MR, Brackett MA, Rivers SE, White M, Salovey P. Classroom emotional climate, student engagement, and academic achievement. J Educ Psychol 2012; 104(3): 700-12.

[http://dx.doi.org/10.1037/a0027268]

[34] Ryan AM, Shim SS. Changes in help seeking from peers during early adolescence: Associations with changes in achievement and perceptions of teachers. J Educ Psychol 2012; 104(4): 1122-34. [http://dx.doi.org/10.1037/a0027696]

[35] Cushman S, West R. Precursors to college student burnout: Developing a typology of understanding. Qual Res Reports Commun 2006; 7(1): 23-31.

[http://dx.doi.org/10.1080/17459430600964638]

[36] Hughes K, Coplan RJ. Why classroom climate matters for children high in anxious solitude: A study of differential susceptibility. Sch Psychol Q 2018; 33(1): 94-102.

[http://dx.doi.org/10.1037/spq0000201] [PMID: 28318284]

[37] Lin Y, Durbin JM, Rancer AS. Perceived instructor argumentativeness, verbal aggressiveness, and classroom communication climate in relation to student state motivation and math anxiety. Commun Educ 2017; 66(3): 330-49. [http://dx.doi.org/10.1080/03634523.2016.1245427]

[38] Radišić J, Videnović M, Baucal A. Math anxiety-contributing school and individual level factors. Eur J Psychol Educ 2015; 30(1): 1-20. [http://dx.doi.org/10.1007/s10212-014-0224-7]

[39] Rigby K. Effects of peer victimization in schools and perceived social support on adolescent well-being. J Adolesc 2000; 23(1): 57-68. [http://dx.doi.org/10.1006/jado.1999.0289] [PMID: 10700372]

[40] Romano L, Buonomo I, Callea A, Fiorilli C. Alexithymia in Young people's academic career: The mediating role of anxiety and resilience. J Genet Psychol 2019; 180(4-5): 157-69.

[http://dx.doi.org/10.1080/00221325.2019.1620675]

[PMID: 31165680]

[41] Scrimin S, Moscardino U, Altoè G, Mason L. Attentional bias for academic stressors and classroom climate predict adolescents' grades and socioemotional functioning. J Res Adolesc 2018; 28(1): 245-58. [http://dx.doi.org/10.1111/jora.12329] [PMID: 29460361]

[42] Ryan AM, Patrick H. The classroom social environment and changes in adolescents' motivation and engagement during middle school. Am Educ Res J 2001; 38(2): 437-60.

[http://dx.doi.org/10.3102/00028312038002437]

[43] Jensen MT, Solheim OJ, Idsøe EMC. Do you read me? Associations between perceived teacher emotional support, reader self-concept, and reading achievement. Soc Psychol Educ 2019; 22(2): 247-66. [http://dx.doi.org/10.1007/s11218-018-9475-5]

[44] Jia Y, Konold TR, Cornell D. Authoritative school climate and high school dropout rates. Sch Psychol Q 2016; 31(2): 289-303. [http://dx.doi.org/10.1037/spq0000139] [PMID: 26641957]

[45] John LC kin, Frances LL mui, Hin-wah W. Development of a classroom environment scale in hong kong. Educ Res Eval 2003; 9(4): 317-44.

[http://dx.doi.org/10.1076/edre.9.4.317.17813]

[46] Patrick H, Kaplan A, Ryan AM. Positive classroom motivational environments: convergence between mastery goal structure and classroom social climate. J Educ Psychol 2011; 103(2): 367-82. [http://dx.doi.org/10.1037/a0023311]

[47] Wagner W, Göllner R, Helmke A, Trautwein U, Lüdtke O. Construct validity of student perceptions of instructional quality is high, but not perfect: Dimensionality and generalizability of domain-independent assessments. Learn Instr 2013; 28: 1-11.

[http://dx.doi.org/10.1016/j.learninstruc.2013.03.003]

[48] Davidson AJ, Gest SD, Welsh JA. Relatedness with teachers and peers during early adolescence: An integrated variable-oriented and personoriented approach. J Sch Psychol 2010; 48(6): 483-510. [http://dx.doi.org/10.1016/j.jsp.2010.08.002] [PMID: 21094395]

[49] Furrer C, Skinner E. Sense of relatedness as a factor in children's academic engagement and performance. J Educ Psychol 2003; 95(1): 148-62.

[http://dx.doi.org/10.1037/0022-0663.95.1.148]

[50] Koth CW, Bradshaw CP, Leaf PJ. Teacher observation of classroom adaptation-checklist: Development and factor structure. Meas Eval Couns Dev 2009; 42(1): 15-30.

[http://dx.doi.org/10.1177/0748175609333560]

[51] Longobardi C, Gastaldi FGM, Prino LE, Pasta T, Settanni M. Examining student-teacher relationship from students' point of view: Italian adaptation and validation of the young children's appraisal of teacher support questionnaire. Open Psychol J 2017; 9(1): 176-87. [http://dx.doi.org/10.2174/1874350101609010176]

[52] Wentzel KR. Are effective teachers like good parents? Teaching styles and student adjustment in early adolescence. Child Dev 2002; 73(1): 287-301.

[http://dx.doi.org/10.1111/1467-8624.00406] [PMID: 14717258]

[53] Wentzel KR. Teacher-student relationships.Handbook of motivation at school. London, UK: Routledge 2016; pp. 211-30.

[54] Fiorilli C, Grimaldi Capitello T, Barni D, Buonomo I, Gentile S. Predicting adolescent depression: The interrelated roles of self-esteem and interpersonal stressors. Front Psychol 2019; 10: 565. [http://dx.doi.org/10.3389/fpsyg.2019.00565] [PMID: 30930823]

[55] Holmbeck GN, Friedman D, Abad M, Jandasek B. Development and psychopathology in adolescence. Behavioral and emotional disorders in adolescents: Nature, assessment, and treatment. New York, NY, US: Guilford Publications 2006; pp. 21-55.

[56] Maciejewski DF, van Lier PAC, Branje SJT, Meeus WHJ, Koot HM. A daily diary study on adolescent emotional experiences: Measurement invariance and developmental trajectories. Psychol Assess 2017; 29(1): 35-49.

[http://dx.doi.org/10.1037/pas0000312] [PMID: 27099977]

[57] Pilkauskaite-Valickiene R, Zukauskiene R, Raiziene S. The role of attachment to school and open classroom climate for discussion on adolescents' school-related burnout. Procedia Soc Behav Sci 2011; 15: 637-41.

[http://dx.doi.org/10.1016/j.sbspro.2011.03.155]

[58] Kim B, Jee S, Lee J, An S, Lee SM. Relationships between social support and student burnout: A meta-analytic approach. Stress Health 2018; 34(1): 127-34.

[http://dx.doi.org/10.1002/smi.2771] [PMID: 28639354]

[59] Cassidy DJ, King EK, Wang YC, Lower JK, Kintner-Duffy VL. Teacher work environments are toddler learning environments: teacher professional well-being, classroom emotional support, and toddlers' emotional expressions and behaviours. Early Child Dev Care 2017; 187(11): 1666-78.

[http://dx.doi.org/10.1080/03004430.2016.1180516]

[60] Hamre BK, Pianta RC. Can instructional and emotional support in the first-grade classroom make a difference for children at risk of school failure? Child Dev 2005; 76(5): 949-67.

[http://dx.doi.org/10.1111/j.1467-8624.2005.00889.x] [PMID: 16149994]

[61] Malecki CK, Demaray MK. Measuring perceived social support: Development of the Child and Adolescent Social Support Scale (CASSS). Psychol Sch 2002; 39(1): 1-18.

[http://dx.doi.org/10.1002/pits.10004]

[62] Bekken F, Beld M, Roest J, van der Helm P, de Swart J, Stams GJJ. Manual SCI : School Climate Inventory. The Youth Expert Centre of Leiden University of Professional Sciences 2015; pp. 1-16.

[63] Organisation for Economic Co-operation and Development. PISA 2015 Results (Volume III): Students' Well-Being OECD Publishing. 2017.

[64] Cavrini G, Chianese G, Bocch B. Behavioral LD-P-S and, 2015 U. School Climate: Parents', students' and teachers' perceptions. Procedia Soc Behav Sci 2015; 191: 2044-8. [http://dx.doi.org/10.1016/j.sbspro.2015.04.641] 
[65] Kasen S, Johnson J, Cohen P. The impact of school emotional climate on student psychopathology. J Abnorm Child Psychol 1990; 18(2): 165-77.

[http://dx.doi.org/10.1007/BF00910728] [PMID: 2348030]

[66] Kikas E, Tang X. Child-perceived teacher emotional support, its relations with teaching practices, and task persistence. Eur J Psychol Educ 2019; 34(2): 359-74

[http://dx.doi.org/10.1007/s10212-018-0392-y]

[67] Schenke K. From structure to process: Do students' own construction of their classroom drive their learning? Learn Individ Differ 2018; 62: 36-48.

[http://dx.doi.org/10.1016/j.lindif.2018.01.006]

[68] Wang M T. School climate support for behavioral and psychological adjustment: Testing the mediating effect of social competence. Sch Psychol Q 2009; 24(4): 240-51.

[http://dx.doi.org/10.1037/a0017999]

[69] Organisation for Economic Co-operation and Development. Pisa 2018 Results (Volume I): What Students Know and Can Do OECD Publishing. 2019.

[70] Allen JP, Pianta RC, Gregory A, Mikami AY, Lun J. An interactionbased approach to enhancing secondary school instruction and student achievement. Science 2011; 333(6045): 1034-7.

[http://dx.doi.org/10.1126/science.1207998] [PMID: 21852503]

[71] Associazione Italiana di Psicologia AIP. Code of ethics of the Italian Psychological Association 2015. Available from: https://aipass.org/node/11560

[72] Baroncelli A, Tambasco G, Ciucci E. Supporto sociale dato e ricevuto nelle relazioni tra pari a scuola: Proposta di un breve questionario selfreport. G Ital Psicol 2016; 43(1-2): 329-45.

[73] Fiorilli C, De Stasio S, Di Chiacchio C, Pepe A, Salmela-Aro K. School burnout, depressive symptoms and engagement: Their combined effect on student achievement. Int J Educ Res 2017; 84: $1-12$

[http://dx.doi.org/10.1016/j.ijer.2017.04.001]

[74] Fiorilli C, Galimberti V, De Stasio S, Di Chiacchio C, Albanese O. L'utilizzazione dello School Burnout Inventory (SBI) con studenti Italiani di scuola superiore di primo e secondo grado. Psicol Clin Sviluppo 2014; 18(3): 403-23.

[http://dx.doi.org/10.1449/78365]

[75] De Beni R, Zamperlin C, Meneghetti C, et al. Test AMOS-Abilità e motivazione allo studio: Prove di valutazione e orientamento per la scuola secondaria di secondo grado e l'università: Nuova edizione. Trento: Edizioni Centro Studi Erickson 2014.

[76] Barbaranelli C. Analisi dei dati: Tecniche multivariate per la ricerca psicologica e sociale. Milano: Edizioni Universitarie di Lettere
Economia Diritto 2007

[77] Muthén LK, Muthén BO. Mplus user's guide 2007. Los Angeles: Muthen \& Muthen 2013

[78] Hooper D, Coughlan J, Mullen MR. Structural equation modelling: Guidelines for determining model fit. Electron J Bus Res Methods 2008; 6(1): 53-60.

[79] Chirumbolo A, Urbini F, Callea A, Lo Presti A, Talamo A. Occupations at risk and organizational well-being: An empirical test of a job insecurity integrated model. Front Psychol 2017; 8: 2084 [http://dx.doi.org/10.3389/fpsyg.2017.02084] [PMID: 29250013]

[80] Satorra A, Bentler PM. A scaled difference chi-square test statistic for moment structure analysis. Psychometrika 2001; 66(4): 507-14. [http://dx.doi.org/10.1007/BF02296192]

[81] George D, Mallery P. SPSS for Windows step by step: A simple guide and reference 110 update. $4^{\text {th }}$ ed. Boston: Allyn \& Bacon 2003.

[82] Fornell C, Larcker DF. Evaluating Structural Equation Models with Unobservable Variables and Measurement Error. J Mark Res 1981; 18(1): 39-50.

[http://dx.doi.org/10.1177/002224378101800104]

[83] Barile JP, Donohue DK, Anthony ER, Baker AM, Weaver SR, Henrich CC. Teacher-student relationship climate and school outcomes: implications for educational policy initiatives. J Youth Adolesc 2012; 41(3): 256-67.

[http://dx.doi.org/10.1007/s10964-011-9652-8] [PMID: 21404108]

[84] McDonald Connor C, Son SH, Hindman AH, Morrison FJ. Teacher qualifications, classroom practices, family characteristics, and preschool experience: Complex effects on first graders' vocabulary and early reading outcomes. J Sch Psychol 2005; 43(4): 343-75. [http://dx.doi.org/10.1016/j.jsp.2005.06.001]

[85] Hafen CA, Allen JP, Mikami AY, Gregory A, Hamre B, Pianta RC. The pivotal role of adolescent autonomy in secondary school classrooms. J Youth Adolesc 2012; 41(3): 245-55. [http://dx.doi.org/10.1007/s10964-011-9739-2] [PMID: 22198156]

[86] Hagenauer G, Hascher T, Volet SE. Teacher emotions in the classroom: associations with students' engagement, classroom discipline and the interpersonal teacher-student relationship. Eur J Psychol Educ 2015; 30(4): 385-403.

[http://dx.doi.org/10.1007/s10212-015-0250-0]

[87] Lee JS. The effects of the teacher-student relationship and academic press on student engagement and academic performance. Int J Educ Res 2012; 53: 330-40.

[http://dx.doi.org/10.1016/j.ijer.2012.04.006]

[88] Pedon A. Dizionario di statistica e metodologia per le scienze del comportamento 2009 .

\section{(C) 2020 Romano et al.}

This is an open access article distributed under the terms of the Creative Commons Attribution 4.0 International Public License (CC-BY 4.0), a copy of which is available at: https://creativecommons.org/licenses/by/4.0/legalcode. This license permits unrestricted use, distribution, and reproduction in any medium, provided the original author and source are credited. 